\title{
PW 2374 prevalence and predictors of proper usage of child safety motorcycle helmet among Tamil primary school students in Hulu Langat district
}

\begin{abstract}
According to Royal Malaysia Police (2013) the number of road traffic crashes increased 31. $5 \%$ from 2004-2013. In 2003 the total road traffic crashes was 326815 out of $13,764,837$ registered vehicles. While in 2013, total road traffic crashes was 477204 out of 23,434,640 total registered vehicles. The number of total road traffic crashes increased simultaneously with the total number of registered vehicles. Total motorcycle that involve in road traffic crashes increases from 2004 until 2013 with $22.6 \%$. Out of 121700 motorcycles that involve in road traffic crashes in 2013, 11260 riders and 1435 pillions experienced death and casualties. Motorcycle riders and pillion riders often suffer from multiple injuries after road traffic collision with head injury being the most common. Among the riders and the pillions, pillions were the one who always get injured on their head compare to the riders. The fact that everyone knows is, wearing motorcycle helmet can reduce head injury during collisions, if it's worn properly. Both the rider and pillion rider were observed on the proper motorcycle helmet usage (wearing a motorcycle helmet, wearing a standard motorcycle helmet, and buckling up the chinstrap properly). They were observed when they are travelling to and from school. Self administrative questionnaire was given to parents to be filled up. The respondents were aged from seven to eleven years old. Response rate for this study was $80.2 \%$. Out of 203 respondents, only $2.5 \%$ children observed to use proper standard child safety motorcycle helmet. Meanwhile, $67.5 \%$ of the riders used proper standard motorcycle helmet. Prevalence of helmet usage among riders with only one pillion rider is $1.5 \%$ compare to with more than one pillion rider is $1.0 \%$. Majority of the parents are lack of knowledge on the existence of standard child safety motorcycle helmet in market.
\end{abstract}

